\title{
MANEJO DO ETILENO E SUA RELAÇÃO COM A MATURAÇÃO DE MAÇÃS ‘GALA’ ARMAZENADAS EM ATMOSFERA CONTROLADA $\left({ }^{1}\right)$
}

\author{
AURI BRACKMANN $\left({ }^{2 *}\right)$; ANDERSON WEBER $\left({ }^{2}\right)$; IVAN SESTARI $\left({ }^{3}\right)$; MIGUEL EDEVALDO PETERLE $\left({ }^{2}\right)$; \\ VANDERLEI BOTH $\left({ }^{2}\right)$; ELIZANDRA PIVOTTO PAVANELLO $\left({ }^{2}\right)$; JOSUEL ALFREDO VILELA PINTO $\left({ }^{2}\right)$
}

\begin{abstract}
RESUMO
O objetivo deste trabalho foi avaliar a qualidade da maçã 'Gala' submetida a diferentes formas de manejo do etileno, por meio da inibição da síntese, inibição da ação e ainda pela sua absorção na câmara de armazenamento, associado a duas temperaturas. Os tratamentos utilizados originaram-se da combinação de duas temperaturas $\left(0,5{ }^{\circ} \mathrm{C}\right.$ e $\left.-0,5{ }^{\circ} \mathrm{C}\right)$ e da aplicação de aminoetoxivinilglicina (AVG) e de 1 metilciclopropeno (1-MCP) além da absorção do etileno, sendo todos os tratamentos armazenados em atmosfera controlada (AC) com 1,2 $\mathrm{kPa} \mathrm{O}_{2}$ e 2,5 kPa $\mathrm{CO}_{2}$. As avaliações da maturação e qualidade dos frutos foram realizadas após oito meses de armazenamento e após este tempo mais sete dias de exposição a $20{ }^{\circ} \mathrm{C}$. A aplicação de AVG manteve a epiderme dos frutos mais verde na saída da câmara. Após sete dias a $20{ }^{\circ} \mathrm{C}$, o tratamento com AVG proporcionou frutos com cor de fundo mais verde, com menor incidência de podridão, maior firmeza de polpa e menor incidência de degenerescência senescente. A menor produção de etileno dos frutos tratados com AVG propiciou baixa respiração, mantendo mais altos os níveis de acidez. A temperatura de $0,5^{\circ} \mathrm{C}$ promoveu significativa manutenção da acidez titulável total e menor incidência de degenerescência senescente, quando comparada com a temperatura de $-0,5$ ${ }^{\circ} \mathrm{C}$. A absorção de etileno e a aplicação de 1-MCP foram eficientes no controle da degenerescência senescente e da perda de firmeza, porém foram menos eficientes que o tratamento com AVG.
\end{abstract}

Palavras-chave: aminoetoxivinilglicina, 1-metilciclopropeno, ACC oxidase.

\section{ABSTRACT \\ ETHYLENE MANAGEMENT AND ITS RELATIONSHIP WITH RIPENING OF 'GALA' APPLES STORED ON CONTROLLED ATMOSPHERE}

This research aimed to evaluate the quality of Gala apples submitted to different ways of ethylene handling, through inhibition of synthesis, inhibition of action and ethylene absorption in storage room, associated with two temperatures. The treatments originated from the combination between two temperatures $\left(0.5^{\circ} \mathrm{C} \mathrm{e}-0.5^{\circ} \mathrm{C}\right)$ and application of aminoethoxyvinylglycine (AVG), 1- methylcyclopropene (1-MCP) and ethylene absorption. All treatments were stored in controlled atmosphere with $1.2 \mathrm{kPa} \mathrm{O}_{2}$ $+2.5 \mathrm{kPa} \mathrm{CO}_{2}$. Ripening and quality evaluations were carried out after eight months of storage more seven days at $20{ }^{\circ} \mathrm{C}$. Preharvest AVG application maintained fruit skin greener at the opening of storage rooms. After seven days at $20^{\circ} \mathrm{C}$, the treatment with AVG resulted in greener skin, with lesser decay incidence, higher flesh firmness and less senescent breakdown incidence. The lower ethylene production of AVG-treated apples resulted in lower respiration and highest titratable acidity levels. The temperature of $0.5{ }^{\circ} \mathrm{C}$ maintained higher of the titratable acidity and reduced senescent breakdown incidence when compared with the temperature of $-0.5{ }^{\circ} \mathrm{C}$. The ethylene absorption and 1-MCP application were also efficient in the control of the senescent breakdown and loss of firmness, however less effective than AVG treatment.

Key words: aminoethoxyvinylglycine, 1- methylcyclopropene, ACC oxidase.

$\left({ }^{1}\right)$ Recebido para publicação em 5 de dezembro de 2007 e aceito em 6 de janeiro de 2009.

$\left({ }^{2}\right)$ Departamento de Fitotecnia, Universidade Federal de Santa Maria, 97105-900 Santa Maria (RS), Brasil. E-mail: auribrackmann@gmail.com $\left(^{*}\right)$ Autor correspondente.

$\left(^{3}\right)$ Programa de Pós-Graduação em Fisiologia e Bioquímica de Plantas da Escola Superior de Agricultura "Luiz de Queiroz" (ESALQ), Universidade de São Paulo (USP), Piracicaba, SP, Brasil. 


\section{INTRODUÇÃO}

Dentre as cultivares de maçãs, a 'Gala' possui alta taxa de produção autocatalítica de etileno $\left(\mathrm{C}_{2} \mathrm{H}_{4}\right)$ e um rápido amadurecimento (BRACKMANN, 1992). O etileno é um hormônio que regula muitos eventos fisiológicos que culminam na ocorrência de perdas pré e pós-colheita de maçãs, sendo o seu controle um dos principais fatores para a redução destas perdas.

O amadurecimento rápido da maçã 'Gala' é resultante da sua alta sensibilidade ao etileno e da alta taxa respiratória, mesmo durante o armazenamento em baixa temperatura ou em atmosfera controlada (Bufler e Streif, 1986). Consequentemente, verifica-se um metabolismo póscolheita acelerado e rápida perda de qualidade, com redução da firmeza de polpa e da acidez titulável total, bem como aumento na ocorrência de distúrbios fisiológicos e podridões (BRACKMANN e SAQUET, 1999). Para retardar a maturação, é necessária a inibição da síntese ou da ação do etileno.

Pode-se reduzir a ação do etileno sobre a maturação de frutos mediante da sua absorção logo após ser produzido e/ou pela aplicação do composto volátil 1-metilciclopropeno (1-MCP), que age ligandose irreversivelmente ao receptor do etileno em nível de membrana celular. Neste processo inibe-se o estímulo fisiológico e a transdução de sinal, influenciando a velocidade de amadurecimento (SISLER e SEREK, 1997). Além de estender a vida pós-colheita e manter a qualidade de maçãs, o 1-MCP reduz a incidência de podridões (MIR e BEAUdRY, 2000) e distúrbios fisiológicos, como escaldadura e escurecimento interno da polpa das maçãs (FAN et al., 1999). BRACKMANN et al. (2003), verificaram que a absorção do etileno na câmara de armazenamento diminuiu a incidência de degenerescência senescente e aumentou a firmeza dos frutos, quando comparado com frutos expostos ao etileno durante o armazenamento.

A aminoetoxivinilglicina (AVG; ácido [S]-trans2-amino-4-[2'-aminoetoxi]-3-butenóico) é um composto que se liga de forma reversível à enzima 1aminociclopropano-1-carboxílico (ACC) sintase, (HUAI ET AL., 2001), impedindo a conversão de S-adenosilmetionina a ácido 1-aminociclopropano-1-carboxílico (ACC), o precursor imediato na rota de biossíntese do etileno (KeNDE, 1993), inibindo assim sua síntese. A AVG diminui a queda pré-colheita de frutos e retarda a maturação da maçã 'Gala' (STEFFENS, 2003), além de inibir a síntese de $\alpha$-farneseno, composto envolvido no surgimento da escaldadura superficial em maçãs e peras (Ju e BRAMLAGE, 2001). Assim, a aplicação de AVG, além de melhorar a manutenção da qualidade dos frutos durante o armazenamento, também retarda o desenvolvimento da cor vermelha na epiderme de maçãs 'Gala' durante os estádios pré-colheita.

A temperatura de armazenamento exerce importante papel na conservação das qualidades físico-químicas dos frutos e na prevenção e/ou diminuição da incidência de doenças e distúrbios fisiológicos. A cultivar Gala conserva-se muito bem em temperaturas entre $0{ }^{\circ} \mathrm{C}$ e $2{ }^{\circ} \mathrm{C}$, não ocorrendo perdas acentuadas de firmeza de polpa (Little e Peggie, 1987). Entretanto, caso a temperatura permaneça muito baixa, podem ocorrer desordens fisiológicas (FIDLER e NORTH, 1967). BRACKMANN et al. (2000) verificaram que a melhor temperatura de armazenamento da maçã 'Gala' em atmosfera controlada (AC) é $0,5^{\circ} \mathrm{C}$, quando comparada com frutos armazenados em $-0,5^{\circ} \mathrm{C}$, pois diminui a incidência de degenerescência interna e polpa farinhenta.

O objetivo deste trabalho foi avaliar a qualidade da maçã 'Gala' armazenada em atmosfera controlada submetida a diferentes formas de manejo do etileno, mediante a inibição da síntese, da ação e também pela sua absorção na câmara de armazenamento, associado a duas temperaturas.

\section{MATERIAL E MÉTODOS}

O experimento foi realizado com frutos de maçã da cultivar Gala provenientes de um pomar comercial localizado no município de Vacaria (RS). Antes do armazenamento foi realizada a seleção dos frutos e a homogeneização das amostras experimentais, sendo eliminados os frutos com lesões e com calibre inferior a 100 (100 frutos por caixa de $18 \mathrm{~kg}$ ) e acima de 180 , objetivando obter amostras homogêneas. Os frutos estavam no momento da colheita com: firmeza de polpa de $72,8 \mathrm{~N}$; acidez titulável de 4,45 meq100 $\mathrm{mL}^{-1}$; sólidos solúveis (SS) de $12,4{ }^{\circ} \mathrm{Brix}$, índice iodo-amido (1-10) de 7,54 e cor em ângulo hue 95,38 e croma de 47,73.

A análise de variância foi realizada segundo o delineamento experimental inteiramente casualizado, em esquema bifatorial $(4 \times 2) \times 4$ ((manejo do etileno $x$ temperatura) $x$ repetição), com utilização de dois fatores qualitativos (temperaturas e inibição da síntese e da ação do etileno). As unidades experimentais foram compostas por 25 frutos.

Os frutos foram armazenados em minicâmaras experimentais com volume de 0,232 $\mathrm{m}^{3}$, acondicionadas em câmaras frigoríficas com volume de $45 \mathrm{~m}^{3}$. Foram avaliados os seguintes tratamentos: [1] AC (testemunha); [2] AC + baixo etileno $(<0,08 \mathrm{ppm})$ [3] AC + aminoetoxivinilglicina (AVG); [4] AC + 1- 
metilciclopropeno (1-MCP), todos submetidos à atmosfera controlada (AC) com 1,2 $\mathrm{kPa} \mathrm{O}_{2}+2,5 \mathrm{kPa}$ $\mathrm{CO}_{2}$, nas temperaturas de $0,5{ }^{\circ} \mathrm{C}$ e $-0,5{ }^{\circ} \mathrm{C}$, com variação máxima de $0,1{ }^{\circ} \mathrm{C}$ para mais ou para menos.

A umidade no interior das minicâmaras foi mantida em torno de $95 \%$ a $97 \%$, sendo monitorada com o auxílio de um psicrômetro.

No tratamento com baixo etileno utilizou-se sachês do Always fresh ${ }^{\circledR}$ que contêm "pellets" impregnados com permanganato de potássio. Os sachês foram colocados no interior da minicâmara, na proporção de um sachê de 10 gramas para cada dois quilos de maçã, que absorveria o etileno produzido pelos frutos. Os níveis de etileno foram monitorados a cada três semanas, através da retirada de uma amostra de gás de $1 \mathrm{~mL}$ do interior da minicâmara e injeção em um cromatógrafo a gás da marca Varian, equipado com um detector de ionização por chama (FID) e coluna Porapak N80/100. Para esta análise, a temperatura da coluna, injetor e detector foram de 90 , 140 e $200{ }^{\circ} \mathrm{C}$, respectivamente. O nível mínimo de etileno detectado pelo aparelho é de $0,08 \mu \mathrm{L} \mathrm{L}^{-1}$, sendo toda leitura com zero de etileno considerada como baixo etileno.

A fonte de AVG foi o produto Retain, com $15 \%$ de ingrediente ativo. A aplicação do produto nas macieiras foi realizada 30 dias antes da colheita e de forma mecanizada, com um turboatomizador com capacidade de $2.000 \mathrm{~L}$ acoplado a um trator. O volume da calda utilizado foi de $1.000 \mathrm{~L} \mathrm{ha}^{-1}$. O espalhante adesivo utilizado foi o Iharaguen-S, do grupo alquilfenol-etoxilado, na concentração de $0,01 \%(\mathrm{v} / \mathrm{v})$.

No tratamento com 1-MCP utilizou-se o produto Smartfresh ${ }^{\circledR}(0,14 \%)$, ajustando a concentração para $900 \mathrm{~nL} \mathrm{~L}{ }^{-1}$. O produto foi solubilizado em $25 \mathrm{~mL}$ de água destilada e deionizada em recipiente hermético e, posteriormente, a solução foi transferida para uma placa de Petri, já no interior da minicâmara, que foi imediatamente fechada. Os frutos ficaram expostos ao tratamento com 1-MCP por 24 horas a $0,5^{\circ} \mathrm{C}$ e, em seguida, as minicâmaras foram ventiladas com o auxílio de uma bomba de sucção com vazão de $14 \mathrm{~m}^{3} \mathrm{~h}^{-1}$ durante uma hora.

A condição de AC foi estabelecida pela diluição do $\mathrm{O}_{2}$ das minicâmaras através da injeção de $\mathrm{N}_{2}$, demorando cerca de duas horas até atingir a condição pré-estabelecida. A pressão parcial de $\mathrm{CO}_{2}$ foi obtida através da injeção do gás no interior da minicâmara até a condição desejada. Devido ao processo de respiração dos frutos, houve consumo de $\mathrm{O}_{2}$ e aumento de $\mathrm{CO}_{2}$, porém a manutenção de níveis constantes dos gases foi assegurada por um equipamento automático da marca Kronenberger/
Climasul SystemtechnikÒ. O equipamento analisou diariamente as concentrações de gases das minicâmaras. Para a correção do $\mathrm{O}_{2}$ consumido pela respiração dos frutos, utilizou-se a injeção de ar atmosférico no interior das minicâmaras. $\mathrm{O} \mathrm{CO}_{2} \mathrm{em}$ excesso, resultante do processo respiratório, foi eliminado com o auxílio de um absorvedor, contendo solução de hidróxido de potássio a $40 \%$. O monitoramento da temperatura foi feito diariamente com termômetros de mercúrio de alta precisão introduzidos na polpa de frutos.

As análises da qualidade dos frutos foram realizadas após oito meses de armazenamento e após sete dias de exposição a $20^{\circ} \mathrm{C}$, para simular o período de comercialização. Os parâmetros analisados foram: cor de fundo, podridão, degenerescência senescente, firmeza de polpa, sólidos solúveis, acidez titulável total, respiração e etileno de acordo com metodologia descrita por STEFFENS (2003). As análises de produção de etileno, e $\mathrm{CO}_{2}$ foram realizadas no primeiro, terceiro, quinto e sétimo dias a $20^{\circ} \mathrm{C}$. Para avaliar a atividade da enzima 1-aminociclopropano-1carboxílico (ACC) oxidase, foram retiradas amostras de casca da região equatorial dos frutos de cada unidade experimental, totalizando $3 \mathrm{~g}$. Estas foram imediatamente incubadas em solução contendo 0,1 $\mathrm{mM}$ de ácido 1-aminociclopropano-1-carboxílico (ACC) em $10 \mathrm{mM}$ do tampão MES (ácido 2 (Nmorfolino) etanossulfônico) em pH 6,0. Após 30 minutos, as amostras foram acondicionadas em seringas herméticas de $50 \mathrm{~mL}$, nas quais se adicionou $1 \mathrm{~mL}$ de $\mathrm{CO}_{2}$. Depois de 30 minutos, a concentração de etileno presente nas seringas foi determinada através da leitura em um cromatógrafo a gás, sendo os dados expressos em $\mu \mathrm{L} \mathrm{C}_{2} \mathrm{H}_{4} \mathrm{~kg}^{-1} \mathrm{~h}^{-1}$ (BUFLER, 1986).

Para cada parâmetro avaliado foi efetuada análise da variância, sendo as médias comparadas pelo teste de Tukey com 5\% de probabilidade de erro. As variáveis expressas em porcentagem foram transformadas pela fórmula arco-seno $\sqrt{x / 100}$, antes da análise da variância.

\section{RESULTADOS E DISCUSSÃO}

A aplicação pré-colheita de AVG na maçã 'Gala', independentemente da temperatura de armazenamento, manteve a epiderme dos frutos mais verde na avaliação realizada na saída da câmara e após sete dias de exposição dos frutos a $20^{\circ} \mathrm{C}$ (Tabela 1). Provavelmente, este efeito da AVG está relacionado com a menor atividade das clorofilases. FERRI et al. (2002) sugerem que a AVG atua inibindo a síntese e/ ou a atividade das clorofilases, porém estes mesmos autores afirmam que o mecanismo responsável por este evento não está bem esclarecido. 
Tabela 1. Cor da epiderme e podridão em maçã 'Gala' após oito meses de armazenamento em atmosfera controlada $\left(1,2 \mathrm{kPa} \mathrm{O} \mathrm{O}_{2}+2,5 \mathrm{kPa} \mathrm{CO}\right.$ ) nas temperaturas de $0,5{ }^{\circ} \mathrm{C}$ e $-0,5^{\circ} \mathrm{C}$, e após sete dias de manutenção a $20^{\circ} \mathrm{C}$

\begin{tabular}{|c|c|c|c|c|c|c|c|c|c|}
\hline \multirow{4}{*}{ Tratamentos } & \multicolumn{9}{|c|}{ Cor de Fundo } \\
\hline & \multicolumn{3}{|c|}{ Hue } & \multicolumn{3}{|c|}{ Croma } & \multicolumn{3}{|c|}{ Podridão (\%) } \\
\hline & \multicolumn{2}{|c|}{ Temperatura } & \multirow{2}{*}{ Médias } & \multicolumn{2}{|c|}{ Temperatura } & \multirow{2}{*}{ Médias } & \multicolumn{2}{|c|}{ Temperatura } & \multirow{2}{*}{ Médias } \\
\hline & $0,5^{\circ} \mathrm{C}$ & $-0,5^{\circ} \mathrm{C}$ & & $0,5^{\circ} \mathrm{C}$ & $-0,5^{\circ} \mathrm{C}$ & & $0,5^{\circ} \mathrm{C}$ & $-0,5^{\circ} \mathrm{C}$ & \\
\hline & \multicolumn{9}{|c|}{ Análise na saída da câmara } \\
\hline $\mathrm{AC}$ & 92,6 & 93,9 & $93,3 b^{* *}$ & 50,4 & 47,8 & 49,07 a & 9,5 & 11,8 & $10,7 \mathrm{a}$ \\
\hline $\mathrm{AC}+\mathrm{BE}^{*}$ & 95,0 & 92,9 & $93,9 \mathrm{~b}$ & 48,6 & 49,6 & 49,09 a & 19,2 & 18,8 & $19,0 \mathrm{a}$ \\
\hline $\mathrm{AC}+\mathrm{AVG}$ & 98,1 & 97,5 & $97,8 \mathrm{a}$ & 47,1 & 48,8 & $46,37 \mathrm{~b}$ & 14,0 & 9,2 & $11,6 \mathrm{a}$ \\
\hline $\mathrm{AC}+1-\mathrm{MCP}$ & 98,4 & 94,1 & $93,8 \mathrm{~b}$ & 48,7 & 45,6 & $48,75 \mathrm{a}$ & 15,0 & 14,2 & $14,6 \mathrm{a}$ \\
\hline Médias & $94,8 \mathrm{~A}$ & $94,6 \mathrm{~A}$ & - & $48,7 \mathrm{~A}$ & $47,9 \mathrm{~A}$ & - & $14,4 \mathrm{~A}$ & $13,5 \mathrm{~A}$ & - \\
\hline C V (\%) & - & 2,24 & - & - & 2,76 & - & - & 27,5 & - \\
\hline \multicolumn{10}{|c|}{ Análise após sete dias de exposição a $20^{\circ} \mathrm{C}$} \\
\hline $\mathrm{AC}$ & 90,7 & 87,2 & $88,9 \mathrm{~b}$ & 49,4 & 47,6 & $48,5 \mathrm{a}$ & 34,0 & 30,7 & $32,4 \mathrm{ab}$ \\
\hline $\mathrm{AC}+\mathrm{BE}^{*}$ & 90,0 & 91,9 & $91,0 \mathrm{~b}$ & 49,1 & 49,1 & $49,1 \mathrm{a}$ & 39,8 & 36,4 & 38,1 a \\
\hline $\mathrm{AC}+\mathrm{AVG}$ & 97,0 & 96,8 & 96,9 a & 48,1 & 47,6 & $47,8 \mathrm{a}$ & 30,0 & 20,1 & $25,1 b$ \\
\hline $\mathrm{AC}+1-\mathrm{MCP}$ & 90,2 & 90,9 & $90,5 \mathrm{~b}$ & 47,7 & 47,8 & $47,8 \mathrm{a}$ & 44,0 & 39,5 & $41,7 \mathrm{a}$ \\
\hline Médias & $92,0 \mathrm{~A}$ & $91,7 \mathrm{~A}$ & - & $48,6 \mathrm{~A}$ & $48,0 \mathrm{~A}$ & - & $36,9 \mathrm{~A}$ & $31,7 \mathrm{~A}$ & - \\
\hline CV (\%) & - & 1,95 & - & - & 2,04 & - & - & 13,0 & - \\
\hline
\end{tabular}

$\mathrm{AC}=$ Atmosfera controlada.

* $\mathrm{BE}=$ baixo etileno na câmara.

**Médias seguidas de mesma letra, minúscula nas colunas e maiúscula nas linhas, não diferem entre si pelo teste de Tukey a 5\% de probabilidade de erro.

A ocorrência de podridões não foi influenciada pelos tratamentos na avaliação realizada na saída da câmara, independentemente da temperatura de armazenamento (Tabela 1). Todavia, após a exposição dos frutos por sete dias a $20^{\circ} \mathrm{C}$, verificou-se menor percentual de podridões nos frutos tratados com AVG em campo, não diferindo estatisticamente dos frutos armazenados apenas em AC (controle).

Após oito meses de armazenamento em atmosfera controlada mais sete dias de exposição dos frutos a $20^{\circ} \mathrm{C}$, não foi verificada influência da temperatura sobre a firmeza de polpa e sobre o teor de sólidos solúveis dos frutos. A aplicação précolheita de AVG manteve os frutos com maior firmeza de polpa, contudo não diferindo dos frutos armazenados em AC com baixo etileno (Tabela 2). Este resultado está diretamente relacionado à redução na produção de etileno dos frutos. De acordo com os resultados de Johnston et al. (2001) e MAJumder e MAZumdar (2002), a presença de etileno é necessária para a atividade das enzimas de degradação das paredes celulares. Majumdar e Mazumder (2002) constataram que o aumento na atividade da poligalacturonase foi altamente correlacionado com a evolução de etileno.
A acidez titulável média foi superior nos frutos tratados com AVG e armazenados à temperatura de $0,5^{\circ} \mathrm{C}$ (Tabela 2). De acordo com Huai et al. (2001), ocorre uma ligação entre a AVG e a ACC sintase, inibindo a síntese de etileno e reduzindo o efeito deste fito-hormônio sobre o processo respiratório, responsável pela degradação dos ácidos orgânicos e açúcares. Em frutos armazenados à temperatura de 0,5 ${ }^{\circ} \mathrm{C}$ os valores médios de acidez titulável são estatisticamente superiores aos daqueles armazenados a $-0,5{ }^{\circ} \mathrm{C}$, atingindo valores aceitos pelo mercado consumidor, que gira em torno de 3,5 meq $100 \mathrm{~mL}^{-1}$. Por outro lado, o teor de sólidos solúveis não foi influenciado pelos tratamentos (Tabela 2).

Em frutos tratados com AVG, nota-se menor degenerescência senescente do que a observada nos frutos submetidos aos demais tratamentos, na avaliação realizada após o período de armazenamento a $0,5^{\circ} \mathrm{C}$ mais sete dias a $20^{\circ} \mathrm{C}$ (Tabela 3 ). Resultados semelhantes foram observados por BRACKMANN e Waclawovsky (2001) e WaclaWovsky (2001). Porém, a absorção de etileno e a aplicação de 1-MCP também reduziram significativamente a degenerescência dos frutos em comparação com aqueles armazenados apenas em AC. 
Tabela 2. Firmeza, acidez e sólidos solúveis em maçã 'Gala' após oito meses de armazenamento em atmosfera controlada $\left(1,2 \mathrm{kPa} \mathrm{O}_{2}+2,5 \mathrm{kPa} \mathrm{CO}\right.$ ) nas temperaturas de $0,5{ }^{\circ} \mathrm{C}$ e $-0,5{ }^{\circ} \mathrm{C}$ mais sete dias a $20{ }^{\circ} \mathrm{C}$

\begin{tabular}{|c|c|c|c|c|c|c|c|c|c|}
\hline \multirow{3}{*}{ Tratamentos } & \multicolumn{3}{|c|}{ Firmeza $(\mathrm{N})$} & \multicolumn{3}{|c|}{ Acidez titulável (meq $100 \mathrm{~mL}^{-1}$ ) } & \multicolumn{3}{|c|}{ SS $\left({ }^{\circ}\right.$ Brix $)$} \\
\hline & \multicolumn{2}{|c|}{ Temperatura } & \multirow{2}{*}{ Médias } & \multicolumn{2}{|c|}{ Temperatura } & \multirow{2}{*}{ Médias } & \multicolumn{2}{|c|}{ Temperatura } & \multirow{2}{*}{ Médias } \\
\hline & $0,5^{\circ} \mathrm{C}$ & $-0,5^{\circ} \mathrm{C}$ & & $0,5^{\circ} \mathrm{C}$ & $-0,5^{\circ} \mathrm{C}$ & & $0,5^{\circ} \mathrm{C}$ & $-0,5^{\circ} \mathrm{C}$ & \\
\hline $\mathrm{AC}$ & 52,8 & 49,5 & $51,1 c^{* *}$ & 3,39 & 3,13 & $3,26 \mathrm{~b}$ & 12,6 & 12,4 & $12,5 \mathrm{a}$ \\
\hline $\mathrm{AC}+\mathrm{BE}^{*}$ & 59,5 & 57,0 & $58,3 \mathrm{ab}$ & 3,38 & 3,26 & $3,32 \mathrm{~b}$ & 12,2 & 12,4 & $12,3 \mathrm{a}$ \\
\hline $\mathrm{AC}+\mathrm{AVG}$ & 62,5 & 65,1 & $63,8 \mathrm{a}$ & 3,89 & 3,44 & $3,67 \mathrm{a}$ & 12,5 & 12,1 & $13,3 \mathrm{a}$ \\
\hline $\mathrm{AC}+1-\mathrm{MCP}$ & 61,5 & 54,7 & $58,1 \mathrm{~b}$ & 3,57 & 3,08 & $3,33 \mathrm{~b}$ & 12,3 & 12,2 & $12,2 \mathrm{a}$ \\
\hline Médias & $59,1 \mathrm{~A}$ & $56,6 \mathrm{~A}$ & - & $3,56 \mathrm{~A}$ & $3,23 \mathrm{~B}$ & - & $12,4 \mathrm{~A}$ & $12,3 \mathrm{~A}$ & - \\
\hline $\mathrm{CV}(\%)$ & - & 7,00 & - & - & 4,22 & - & - & 1,83 & - \\
\hline
\end{tabular}

$\mathrm{AC}=$ Atmosfera controlada.

* BE = baixo etileno na câmara.

${ }^{* *}$ Médias seguidas de mesma letra, minúscula nas colunas e maiúscula nas linhas, não diferem entre si pelo teste de Tukey a 5\%.

Tabela 3. Degenerescência senescente e atividade "in vivo" da ACC oxidase em maçã 'Gala' após oito meses de armazenamento em atmosfera controlada $\left(1,2 \mathrm{kPa} \mathrm{O}_{2}+2,5 \mathrm{kPa} \mathrm{CO}_{2}\right)$ nas temperaturas de $0,5^{\circ} \mathrm{C}$ e $-0,5^{\circ} \mathrm{C}$ mais sete dias a $20^{\circ} \mathrm{C}$

\begin{tabular}{|c|c|c|c|c|c|c|}
\hline \multirow{3}{*}{ Tratamentos } & \multicolumn{3}{|c|}{ Degenerescência senescente (\%) } & \multicolumn{3}{|c|}{ ACC oxidase $\left(\mu \mathrm{L} \mathrm{C}_{2} \mathrm{H}_{4} \mathrm{~kg}^{-1} \mathrm{~h}^{-1}\right)$} \\
\hline & \multicolumn{2}{|c|}{ Temperatura } & \multirow{2}{*}{ Médias } & \multicolumn{2}{|c|}{ Temperatura } & \multirow{2}{*}{ Médias } \\
\hline & $0,5^{\circ} \mathrm{C}$ & $-0,5^{\circ} \mathrm{C}$ & & $0,5^{\circ} \mathrm{C}$ & $-0,5^{\circ} \mathrm{C}$ & \\
\hline $\mathrm{AC}$ & 25,0 & 40,6 & $32,8 a^{* *}$ & $144,3 \mathrm{~A} \mathrm{a}$ & $90,7 \mathrm{~B} \mathrm{a}$ & 117,5 \\
\hline $\mathrm{AC}+\mathrm{BE}^{*}$ & 18,3 & 27,3 & $22,8 \mathrm{~b}$ & $85,4 \mathrm{~A} \mathrm{~b}$ & $61,5 \mathrm{~A} \mathrm{ab}$ & 73,4 \\
\hline $\mathrm{AC}+\mathrm{AVG}$ & 11,0 & 15,0 & $13,0 \mathrm{c}$ & $89,7 \mathrm{~A} \mathrm{~b}$ & $90,3 \mathrm{~A}$ a & 90,0 \\
\hline $\mathrm{AC}+1-\mathrm{MCP}$ & 23,0 & 23,2 & $23,1 \mathrm{~b}$ & $45,8 \mathrm{~A} \mathrm{c}$ & $58,0 \mathrm{~A} \mathrm{~b}$ & 51,9 \\
\hline Médias & $19,3 \mathrm{~B}$ & $26,5 \mathrm{~A}$ & - & 91,3 & 75,1 & - \\
\hline $\mathrm{CV}(\%)$ & - & 15,6 & - & - & 15,4 & - \\
\hline
\end{tabular}

$\mathrm{AC}=$ Atmosfera controlada.

* $\mathrm{BE}=$ baixo etileno na câmara.

**Médias seguidas de mesma letra, minúscula nas colunas e maiúscula nas linhas, não diferem entre si pelo teste de Tukey a5\%.

O bloqueio da ação do etileno com 1-MCP reduziu a atividade da ACC oxidase em relação aos demais tratamentos, independentemente da temperatura de armazenamento, apenas não diferindo do tratamento em AC com baixo etileno na temperatura de $-0,5{ }^{\circ} \mathrm{C}$ (Tabela 3). Para a temperatura de $0,5^{\circ} \mathrm{C}$ a atividade da ACC oxidase foi semelhante nos frutos tratados com AVG e nos armazenados em AC com baixo etileno. Este resultado provavelmente decorre do fato de que a AVG impede a formação de ACC, através da inibição da enzima ACC sintase, porém não a conversão de ACC para etileno e, assim, sua eficiência pode ser influenciada pelo nível de ACC previamente presente no tecido (YANG e Hoffman, 1984). Além disso, a AVG pode perder seu efeito sobre a inibição da síntese de etileno com o avanço do estádio de maturação do fruto, pois nova síntese de enzimas ocorre, as quais poderão não ser inibidas pela AVG (LiEBERMAN, 1975). Quando armazenados apenas em AC, nos frutos submetidos à temperatura de $0,5{ }^{\circ} \mathrm{C}$, a atividade da enzima $\mathrm{ACC}$ oxidase foi significativamente maior quando comparada à temperatura de $-0,5^{\circ} \mathrm{C}$.

A taxa de síntese de etileno foi bastante baixa durante o período de sete dias a $20{ }^{\circ} \mathrm{C}$, independentemente da temperatura de armazenamento dos frutos (Figura $1 \mathrm{~A}$ e 1B), mantendo-se abaixo de $0,64 \mu \mathrm{L} \mathrm{C}_{2} \mathrm{H}_{4} \mathrm{~kg}^{-1} \mathrm{~h}^{-1}$ sempre que a $\mathrm{AC}$ foi associada ao baixo etileno na câmara, à aplicação de AVG e à aplicação de 1-MCP. Por outro lado, em maçãs submetidas apenas a AC e armazenadas à temperatura de $0,5{ }^{\circ} \mathrm{C}$, houve acréscimo na síntese de etileno no quinto e no sétimo dia a $20^{\circ} \mathrm{C}$. A maior taxa de produção de etileno nestas condições pode ser explicada pela maior atividade da enzima ACC oxidase, estatisticamente superior no tratamento controle submetido a $0,5{ }^{\circ} \mathrm{C}$ quando comparada à temperatura de $-0,5^{\circ} \mathrm{C}$ (Tabela 3$)$. 
Segundo Hartmann et al. (1987), a síntese de etileno é provocada pela alta temperatura e pela retirada dos frutos das condições de $A C$, que possibilitam aceleração na queda da resistência ao amadurecimento e um estímulo do processo de autocatálise do etileno, o que justifica também o acréscimo na síntese de etileno destes frutos. A aplicação pré-colheita de AVG resultou na menor síntese de etileno, em relação aos demais tratamentos, durante os sete dias a $20^{\circ} \mathrm{C}$ (Figura 1A e 1B).

A aplicação pré-colheita de AVG resultou em significativa redução da atividade respiratória dos frutos quando expostos a $20^{\circ} \mathrm{C}$. Contudo, esse efeito foi mais pronunciado nos frutos tratados com AVG e armazenados à temperatura de $-0,5{ }^{\circ} \mathrm{C}$ (Figura $1 \mathrm{C}$ e $1 \mathrm{D}$ ). WACLAWOVSKY (2001) afirma que, possivelmente, o efeito da AVG sobre a respiração está relacionado à menor produção de etileno pelos frutos, pois a respiração é considerada um processo dependente do etileno (PRE-AYMARD et al., 2002). A atividade respiratória dos frutos tratados com 1-MCP e expostos ao baixo etileno foi semelhante à dos frutos-controle, armazenados somente em AC, com taxa respiratória superior aos frutos tratados com AVG, exceto na análise aos sete dias a $20^{\circ} \mathrm{C}$ na temperatura de $0,5^{\circ} \mathrm{C}$ (Figura 1C e 1D).

Verifica-se, de maneira geral, que o tratamento pré-colheita com AVG reduziu a síntese de etileno e a respiração e, assim, retardou o amadurecimento, reduzindo a perda de firmeza de polpa de maçãs armazenadas em AC. Também proporcionou redução na incidência de distúrbios fisiológicos, aumentando o tempo de vida pós-colheita dos frutos. A absorção de etileno e a aplicação de 1-MCP também reduziram alguns processos fisiológicos da maturação, porém em menor intensidade.
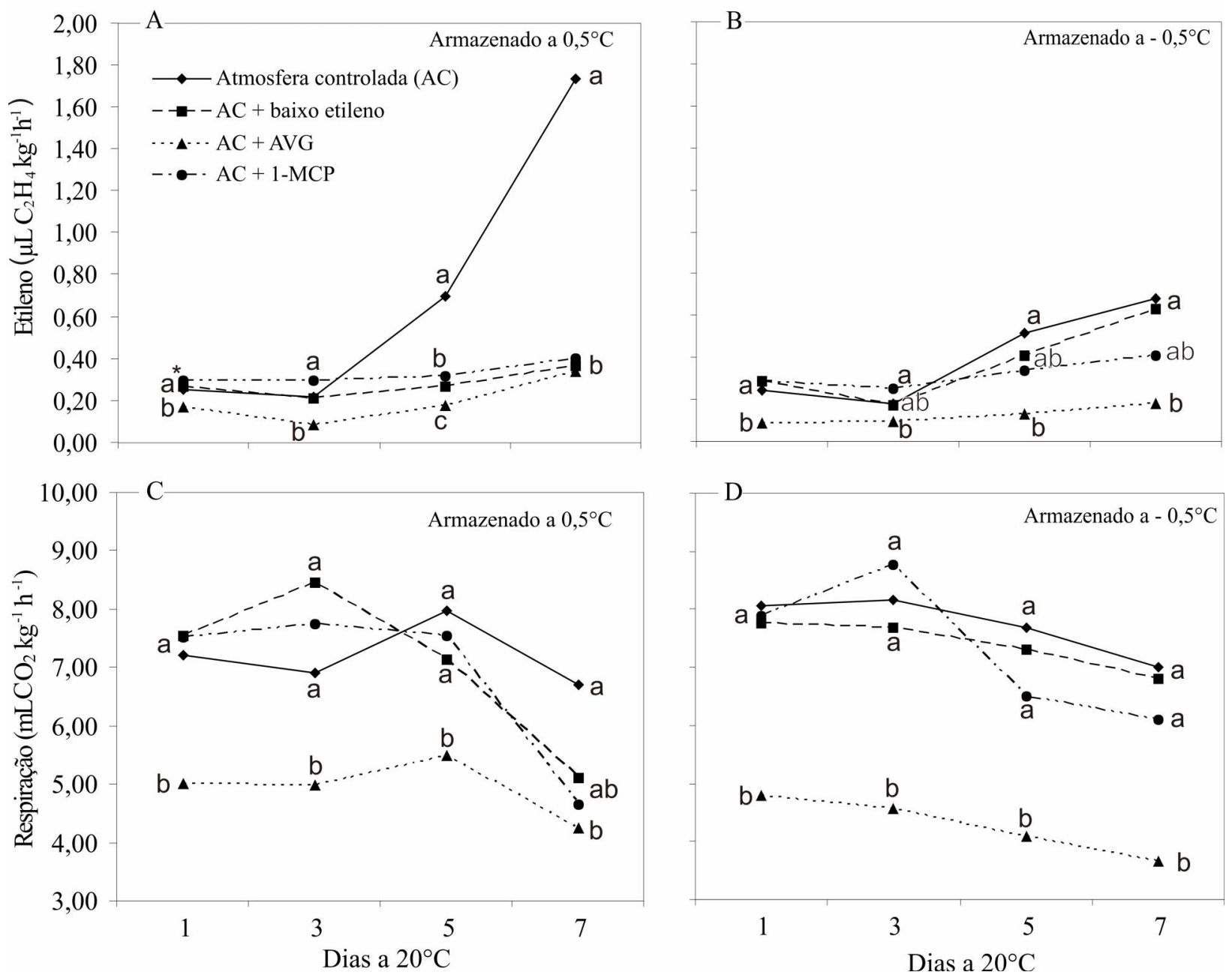

Figura 1. Produção de etileno (A e B) e de $\mathrm{CO}_{2}(\mathrm{C}$ e D) em maçã 'Gala' após oito meses de armazenamento em atmosfera controlada $\left(1,2 \mathrm{kPa} \mathrm{O}_{2}+2,5 \mathrm{kPa} \mathrm{CO}\right)$ mais sete dias a $20{ }^{\circ} \mathrm{C}$. * Pontos seguidos de mesma letra na vertical, dentro de cada parâmetro e momento de avaliação, não diferem entre si pelo teste de Tukey a $5 \%$ de probabilidade de erro. 


\section{CONCLUSÕES}

1. A aplicação pré-colheita de AVG em maçãs 'Gala' associado ao armazenamento em atmosfera controlada na temperatura de $0,5^{\circ} \mathrm{C}$ é de grande eficiência na manutenção da qualidade dos frutos durante oito meses de armazenamento mais sete dias de vida de prateleira, sendo a melhor condição de armazenagem para esta cultivar.

2. Com a absorção de etileno e aplicação de 1-MCP, a eficácia foi inferior à aplicação de AVG no controle da maturação dessa cultivar de maçã.

\section{REFERÊNCIAS}

BRACKMANN, A. Produção de etileno, $\mathrm{CO}_{2}$ e aroma de cultivares de maçã. Revista Brasileira de Fruticultura, Jaboticabal, v.14, n.1, p.103-108,1992.

BRACKMANN, A.; SAQUET, A. A. Qualidade da maçã 'Gala' com rápido resfriamento e instalação da atmosfera controlada e eliminação do etileno da câmara. Revista Brasileira de Fruticultura, Jaboticabal, v.21, n.2, p.177-181, 1999.

BRACKMANN, A.,STEFFENSC. A., NEUWALD, D. A. SESTARI, I. Armazenamento de maçã 'Gala' em atmosfera controlada com remoção de etileno. Ciência Rural, v. 33, n. 4, jul-ago, 2003.

BRACKMANN, A.; STEFFENS, C. A.; WACLAWOVSKY, A. J. Efeito da temperatura e da pressão parcial de $\mathrm{CO}_{2}$ sobre maçã 'Gala' armazenada sob atmosfera controlada contendo pressão parcial ultra-baixa de oxigênio. Revista Ciência e Agrotecnologia, Lavras, v.24, edição especial, p.25-32, 2000.

BRACKMANN, A.; WACLAWOVSKY, A. J. Responses of 'Gala' apples to preharvest treatment with AVG and low ethylene CA storage. Acta Horticulturae, Leuven, n.553, p.155-157, 2001.

BUFLER, G. Ethylene-promoted conversion of 1aminocyclopropene-1-carboxylic acid to ethylene in peel of apple at various stages of fruit development. Plant Physiology, Rockville, v.80, p.539-543, 1986.

BUFLER, G.;STREIF, J. Ethylene biosynthesis of 'Golden Delicious' apples stored in different mixtures of carbon dioxide and oxygen. Scientia Horticulturae, Amsterdan, v.30, p.177-185, 1986.

FAN, X.; MATTHEIS, J. P.; BLANKENSHIP, S. M. Development of apple superficial scald, soft scald, core flush, and greasiness is reduced by MCP. Journal of Agricultural and Food Chemistry. Washington, v. 47, n. 8, p. 3063-306. 1999.

FERRI, V. C.; RINALDI, M. M.; DANIELI, R.; LUCHETTA, L. ROMBALDI, C. V. Controle da maturação de caquis 'Fuyu' com uso de aminoetoxivinilglicina e ácido giberélico. Revista Brasileira de Fruticultura, Jaboticabal, v.24, n.2, p.344-347, 2002.

FIDLER, J.; NORTH, C. J. The effect of conditions of storage on the respiration of apples. I. The effects of temperature and concentrations of carbon dioxide and oxygen on the production of carbon dioxide and uptake of oxigen. Journal of Horticultural Science, London, v.42, p.189-206, 1967.

HARTMANN, C. J. R.; DROUET, A.; MORIN, F. Ethylene and ripening of apple, pear and cherry fruit. Plant Physiology and Biochemistry, Paris, v. 25, n. 4, p. 505-512, 1987.

HUAI, Q. et al. Crystal structures of 1-aminocyclopropane-1carboxylate (ACC) synthase in complex with aminoethoxyvinylglycine and pyridoxal-5' -phosphate provide new insight into catalytic mechanisms. Journal of Biological Chemistry, Maryland, v.276, n.41, p.38210-38216, 2001.

JOHNSTON, J. W.; HEWETT, E. W.; HERTOG, M. L. A. T.; HARKER, F. R. Temperature induces differential softening responses in apple cultivars. Postharvest Biology and Technology, Amsterdam, v.23, n.3, p.185-196, 2001.

JU, Z.; BRAMLAGE, W.J. Developmental changes of cuticular constituents and their association with ethylene during fruit ripening in 'Delicious' apples. Postharvest Biology and Technology, Amsterdam, v.21, p.257-263, 2001.

KENDE, H. Ethylene biosynthesis. Annual Review of Plant Physiology and Molecular Biology, Palo Alto, v.44, p.283-307, 1993.

LIEBERMAN, M. Biosynthesis and action of ethylene. Annual Review of Plant Physiology.,Palo Alto, v. 30, p. 533-591, 1979.

LITTLE,C. R. \& PEGGIE,I. D. Storage injury of pome fruit caused by stress levels of oxygen, carbon dioxide, temperature and ethylene. HortScience, Alexandria, v.22, n.5, p.783-790, 1987.

MAJUMDER, K.; MAZUMDAR, B.C. Changes of pectic substances in developing fruits of cape-gooseberry (Physalis peruviana L.) in relation to the enzyme activity and evolution of ethylene. Scientia Horticulturae, Amsterdam, v.96, n.1-4, p.91-101, 2002.

MIR, N. A.; BEAUDRY, R. M. Use of 1- MCP to reduce the requirement for refrigeration and modified-atmospheres in the storage of apple fruit. In.: INTERNATIONAL CONFERENCE ON POSTHARVEST SCIENCE, Jerusalem, 2000. Abstracts... Jerusalem, Israel: ISHS/ARO, 2000. p.23.

PRE-AYMARD, C.; WEKSLER, A.; LURIE, S. Responses of 'Anna', a rapidly ripening summer apple, to 1-methylcyclopropene. Postharvest Biology and Technology, Amsterdam, 2002.

SISLER, E. C.; SEREK, M. Inhibitors of ethylene responses in plants at the receptor level: recent developments. Physiologia Plantarum, Copenhagen, v.100, p.577-582, 1997.

STEFFENS, C. A. Maturação e qualidade pós-colheita de maçãs, 'Gala' e 'Fuji', com aplicação pré-colheita de aminoetoxivinilglicina e ethephon. 2003. 88f. Dissertação (Mestrado em Agronomia) - Universidade Federal de Santa Maria - UFSM, Santa Maria.

WACLAWOVSKY, A. J. Controle da maturação de maçãs (Malus domestica Borkh.) cv. Gala, com aplicação pré-colheita de aminoetoxivinilglicina (AVG). 2001. 134p. Dissertação (Mestrado em Agronomia) - Universidade Federal de Santa Maria, Santa Maria, 2001.

YANG, S.F.; HOFFMAN, N. E. Ethylene biosynthesis and its regulation in higher plants. Annual Review of Plant Physiology and Plant Molecular Biology, Palo Alto, v.35, p.155-189, 1984. 